International Journal of Environment, Agriculture and Biotechnology
Vol-6, Issue-1; Jan-Feb, 2021
Journal Home Page Available: $\underline{\text { https://ijeab.com/ }}$
Journal DOI: $10.22161 /$ ijeab

\title{
Effect of differential expression of pro-region on the transglutaminase productivity in pichia pastoris
}

\author{
Aqeel Sahibzada Muhammad ${ }^{1,2}$, Al-Adeeb Abdulqader ${ }^{2}$, Waleed AL-Ansi ${ }^{3}$, Sharoon Ejaz ${ }^{1,2}$, Lu \\ $\mathrm{Xia}^{1,2}$, Song $\operatorname{Liu}^{1,2^{*}}$
}

${ }^{1}$ National Engineering Laboratory for Cereal Fermentation Technology, Jiangnan University, 1800 Lihu Road,Wuxi 214122, Jiangsu, China. ${ }^{2}$ School of Biotechnology and Key Laboratory of Industrial Biotechnology, Ministry of Education, Jiangnan University, 1800Lihu Road, Wuxi 214122, Jiangsu, China

${ }^{3}$ School of Food Science and Technology, State Key Laboratory of Food Science and Technology, Jiangnan University, 1800 Lihu Avenue, Wuxi 214122, China.

*Correspondence: Prof. S. Liu liusong@ jiangnan.edu.cn

Received: 03 Dec 2020; Received in revised form: 24 Jan 2021; Accepted: 13 Feb 2021; Available online: 28 Feb 2021

(C)2021 The Author(s). Published by Infogain Publication. This is an open access article under the CC BY license

(https://creativecommons.org/licenses/by/4.0/).

\begin{abstract}
Transglutaminase (TG) induces protein cross-linking by catalyzing the reaction of acyl transfer. Mature sequence of TG is inactive when express without its pro-region. Since pro-region is critical for inhibiting the TG's action and for correctly folding it extracellularly, the production is either poor or forming inclusion bodies without its pro-region. One of the fundamental steps for higher yield to date is to increase the transcriptional level of the recombinant gene by generating multicopies that could only be accomplished by cloning the concatemers. Here, co-expressing strain was successfully generated by incorporating pro-region into ribosomal DNA ( $r D N A$ ) sites to achieve different copies. The maximum enzyme activity was up to $3.9 u / m l$ compared to the wild type that was only $2.1 \mathrm{u} / \mathrm{ml}$ in shake flasks being inducted for 96hrs. This research work provides an important strategy for its pro-region to take advantage of the degree of transglutaminase folding.
\end{abstract}

Keywords - Pichia pastoris, protein folding, pro-peptide, transglutaminase.

\section{INTRODUCTION}

Transglutaminase (EC 2.3.2.13) also called proteinglutamine-gammaglutamyl-transferase belonging to the class of transferase that catalyzes acyl-transfer between residues of glutamine and a wide range of primary amine residues ${ }^{1}$. The reaction leads to stable, insoluble product complexes of macromolecules ${ }^{2}$. The cross-link reaction leads to the creation of an intra- and inter-molecular isopeptide bond that leads to the polymerization of proteins ${ }^{3}$.

TGases, present in vertebrates, invertebrates, molluscs, plants and microorganisms, are considered to be widely distributed in nature $e^{4,5}$. They have myriad functionalities and involved in most of the physiological functions, such aswound healing, epidermal keratinization, blood clotting, plant programmed cell death and photosynthetic complex chloroplast stabilization. In addition, TGases are also widely used in the food industry, biochemical and biomedical research, tissue engineering, and in the development of leather and textiles ${ }^{6-10}$.In early TG studies, calcium dependent mammalian transglutaminases were used to assist in protein polymerization but due to the high-cost, poor reaction kinetics and instability of animal origin TGases, triggered the scientist to look for cheaper TG sources. TG from streptomyces mobaraensis was first identified in 1989 by the researchers of Ajinomoto Co., Inc and currently, majority of the industries used microbial transglutaminase ${ }^{11,12}$. 
Several proteins, proteases in particular, are expressed as inactive precursors that are triggered by the removal of the respective protein pro-region. It is understood that the proregion functions as a protein transporter and inhibitor of the protein concerned ${ }^{13-15}$. MTG produce extracellularly as inactive zymogen and the $\mathrm{N}$-terminal pro-region consisting of 45 amino acids must be removed by exo- or endogenous proteases for fully functional enzyme ${ }^{16}$. Producing recombinant proteins in engineering strains is troublesome for their activation and downstream processing. Keeping in view the activation problem, pichia pastoris is a perfect host with integrated kex2-endpeptipase and capable of separately generating pro- and mature region without needing any in vitro protease.MTG activity reached $1.83 \mathrm{U} / \mathrm{mL}$ in flasks, suggesting that mature enzymes could be promoted and activated by the pro-peptide sequence ${ }^{17}$. However, the processing and manufacturing of MTG acquired so far is not enoughto reach the industry demand.Therefore, to boost the enzyme activity of MTG, a rising demand for MTG is urgently required.

Pichia pastoris carries repeated ribosomal DNA (rDNA) sequence separated by non-transcribed intergenic spacer $(\mathrm{NTS})^{18}$. It could be used as the site of recombination to increase the target genecopy number. TG expression in recombinant host is problematic without its pro-region, having dual role: assisting the folding of TGase into active conformation and preventing its activation ${ }^{14,19}$. The higheryield pro-peptide strategy will be used in this research work, providing the importance of the pro-region for TG.

In order to boost the expression and enzyme activity, the genes for pro- and TG were optimized according to codon bias of pichia pastoris in view of the stable mRNA secondary structures and GC ratio. Two different sites at chromosome were selected for pro- and TG gene insertion. The pro-region inserted at ribosomal DNA repeated sites (rDNA)and TG at the mutant histidinol dehydrogenase site (His4). Both of the genes were regulated by AOX1 promoter. By optimization of fermentation conditions, a high co-expression of propeptide and MTG was obtained compare to wild type.

\section{MATERIALS AND METHODS}

\subsection{General Strains and Vectors}

Strains and vectors are described in Table.1 shown below. The E. coli was cultured in Luria-Bertani (LB) medium at $37{ }^{\circ} \mathrm{C}$, whereas the P. pastoris was cultured in buffered methanol-complex medium (BMMY) at different temperature and $\mathrm{pH}$.

Table 1. Strains and plasmids used in this study

\begin{tabular}{lll}
\hline Strains & Genotype & References \\
\hline E. Coli JM109 & endA1, recA1, gyrA96, thi, hsdR17 (rk-, mk+), relA1, supE44, & Invitrogen \\
& $\Delta($ lac-proAB), [F' traD36, proAB, laqIqZ4M15] & \\
P. Pastoris GS115 & his4, host strain & Invitrogen \\
PPIC9K & Description & Invitrogen \\
pET-22b(+) & Description & Invitrogen \\
pPIC9K-Pro & pPIC9K vector carrying 135bp of pro region, regulated under AOX1 & This study \\
& promoter & \\
pPIC9K-TG & pPIC9K vector carrying 1135bp of mature TG, regulated under & \\
& AOX1 promoter & This study \\
GS115-pro-rDNA & Pro-region integrated at rDNA site of GS115 & This Study \\
GS115(PrDNA/TGhIS4) & Mature sequence of TG integrated at HIS4 site and transferred to & This study \\
\hline
\end{tabular}

\subsection{Construction of wild type Recombinant plasmid}

The $m t g$ gene was selected from the cDNA of S. mobaraensis (accession no. Y18315). The PCR was performed to amplify mTG by using primer TG-F (5'AGAGAGGCTGAAGCTGACAATGGCGCGGGGGAAG
AG-3') as a forward primer and primer TG-R (5'GAATTCTACGTAtcaGTGGTGGTGGTGGTGGTGCG-3') as a reverse primer from the plasmid pET-22b $(+)$. The resultant gene was then cloned into pPIC9K vector by one step cloning. The recombinant vector was transformed into $E$. 
coli JM109, sequenced to ensure base sequence was not mutated.

\subsection{Media Preparation for Subsequent procedures}

(a) YPD Media (g/L): Dissolved 20g peptone and $10 \mathrm{~g}$ yeast extract in $900 \mathrm{~mL}$ while $20 \mathrm{~g}$ glucose in $100 \mathrm{~mL}$ separately. For solid media, 2\% agar was added

(b) BMMY (g/L): $10 \mathrm{~g}$ yeast extract, $20 \mathrm{~g}$ peptone, $100 \mathrm{mM}$ potassium phosphate $\mathrm{pH} 6.0,1.34 \% \mathrm{YNB}, 4$ x 10-5\% biotin, $0.5 \%$ methanol were prepared and sterilized.

(c) MD solid medium (g/L): 1.34\% YNB, 4 x 10$5 \%$ and biotin $2 \%$ dextrose were the recipes used.

\subsection{Pichia GS115 competent cell preparation}

Pichia pastoris GS115 strain was streaked on YPD plate to attain the colonies. After the colonies grew, a single colony was picked and inoculated into $50 \mathrm{~mL}$ YPD medium, and cultured at $30^{\circ} \mathrm{C}$ for $24 \mathrm{~h}$. About $0.5 \mathrm{~mL}$ of the bacterial solution was taken from the culture and inoculate it into another $50 \mathrm{~mL}$ of fresh YPD medium. The media was cultured at OD600 $1.3 \sim 1.5$ at $30^{\circ} \mathrm{C}$. The culture was centrifuged at $1500 \times \mathrm{g}$ and $4^{\circ} \mathrm{C}$ for $5 \mathrm{~min}$. The cells were resuspended in $8 \mathrm{~mL}$ YTB, 180ul DTT and kept it at room temp for $30 \mathrm{~min}$. After, centrifuged it at $1500 \times \mathrm{g}$ and $4^{\circ} \mathrm{C}$ for $5 \mathrm{~min}$. The cells were resuspended and washed in $50 \mathrm{~mL}(1 \mathrm{M}$ sorbitol) at $1500 \times \mathrm{g}$ and $4^{\circ} \mathrm{C}$ for $5 \mathrm{~min}$. This step was repeated three times. Finally, the cells were resuspended by adding $1.0 \mathrm{~mL}$ of $1 \mathrm{M}$ sorbitol and aliquot of $100 \mathrm{ul}$ added in each tube for subsequent transformation.

\subsection{Construction of GS115-Pro-rDNA expression cassette}

The pro-region sequence was copied with forward primer (P1) and reverse primer (P2) and fused to the 3'AOX1 end of $\mathrm{S}$. cerevisiae $\alpha$-mating factor signal sequence. The rDNA sequence was isolated from pichia genome with the forward primer (P3) and reverse primer (P4). The rDNA sequence fused to the 3'end of the 3'AOX1 terminator.The earlier prepared Pichia GS115 competent cells were taken out and thaw them on ice. The recombinant plasmid GS115-Pro were linearized by digesting with SpeI restriction enzyme and transformed into competent cell, kept it for $15 \mathrm{~min}$ on ice. The samples were then transformed to e-cups followed the

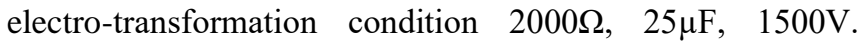
Immediately added $1 \mathrm{~mL}$ of $1 \mathrm{M}$ sorbitol solution after the completion of the transformation and incubate it for $1 \sim 2 \mathrm{hr}$ at $30^{\circ} \mathrm{C}$. Centrifuged the transformed culture at 5000rpm for $3 \mathrm{~min}$. The cells were resuspended and poured on YPD agar plate and incubate it at $30^{\circ} \mathrm{C}$ for 2-3 days.

Table. 2 PCR primers used in this study

\begin{tabular}{ll}
\hline Primers & Sequence direction $\left(\mathbf{5}^{\prime} \rightarrow \mathbf{3}^{\prime}\right)$ \\
\hline$P 1$ & gataacggtgctggtgaagaaacta \\
$P 2$ & tgctggtccatctttagagctcca \\
$P 3$ & tagttaggttaccgttttcctaatatttaagg \\
$P 4$ & gactggtggttgactgttggtggaag \\
\hline
\end{tabular}

\subsection{Screening and Identification of Positive recombinants}

PCR was used to verify positive recombinants of the engineered strain. Eight colonies from the YPD plate were randomly picked, and 5AOX and $3 \mathrm{AOX}$ primers were used for colony PCR. Agarose gel electrophoresis was used to verify that the correct colony number was selected.

\subsection{Construction of the co-expression cassette}

The recombinant vector GS115-Pro successfully transformed to pichia genome to form GS115-Pro-rDNA. The GS115Pro-rDNA strain was used as a host strain for the recombinant vector GS115-TG. As mentioned earlier that the TG gene was isolated from the cDNA of S. mobaraensis was fused to the 3'AOX1 end of S. cerevisiae $\alpha$-mating factor signal sequence. The competent cells were made in the same way from the host train GS115-Pro-rDNA. To linearize the GS115-TG-his4 plasmid for transformation, the SalI restriction enzyme was used. The co-expression strain GS115(PrDNA/TGhIS4) was successfully engineered and cultured on MD plate for $1 \sim 2$ days at $30^{\circ} \mathrm{C}$. Clones with higher growth were selected on YPD with 1-1.5ug concentration of G418. The successful clones from YPD plate were cultured in YPD medium for $24 \mathrm{hr}$ at $30^{\circ} \mathrm{C}$ and induce in BMMY media for expression. In the supernatant, the TG was confirmed by colorimetric hydroxamate based method that gives the color of burgundy by treatment with substrates.

\subsection{GS115(PrDNA/TGhIS4) engineered strain expression in shake flask}

The strain with higher activity was added into 50mL YPD for overnight culture. The overnight culture was centrifuged at $1500 \mathrm{xg}$ for $5 \mathrm{~min}$ at $4^{\circ} \mathrm{C}$ when the OD reached 5 6. The overnight culture was harvested in 50mL BMMY media with different $\mathrm{pH}$ and temperature conditions. $0.5 \%$ methanol was added routinely $24 \mathrm{hr}$ for about $96 \mathrm{hr}$ course of shake flask fermentation. Samples were taken every $24 \mathrm{hr}$ for analysis and enzyme activity was measured by colorimetric hydroxamate method described below. 


\subsection{Enzyme assays and definition of units}

TGase activity was measured by the colorimetric hydroxamate procedure. Enzyme solution (50ul) was mixed with $500 \mathrm{ul}$ of reagent A (50mM MES, $100 \mathrm{mM} \mathrm{NH} 2 \mathrm{OH}$, $10 \mathrm{mM}$ glutathione (reduced form), and $30 \mathrm{mM} \mathrm{N \alpha -CBZ-}$ GLN-GLY, pH 6.0, and incubated at $37^{\circ} \mathrm{C}$ for $10 \mathrm{~min}$. The reaction was stopped by adding $500 \mathrm{ul}$ of reagent $\mathrm{B}(\mathrm{a}, 3 \mathrm{~N}-$ $\mathrm{HCl}$; b, $12 \% \mathrm{TCA}$; c, $5 \% \mathrm{FeCl} 3.6 \mathrm{H} 2 \mathrm{O} ; \mathrm{a}: \mathrm{b}: \mathrm{c}=1: 1: 1)$, and the resulting red color was measured at $525 \mathrm{~nm}$.

\subsection{Data statistical analysis}

Statistical data analyzing was performed with the aid of IBM-SPSS-20 software (SPSS Inc., Chicago, USA). The significant changes among the tested samples were estimated with ANOVA by means of Duncan's test on a confidence level of $95 \%(p \leq 0.05)$. All experiments were accomplished in triplicate and the data were expressed as mean \pm standard deviation.

\section{RESULTS AND DISCUSSION}

\subsection{Constructing the co-expressing strains for Pro- and TG}

Two different vectors pPIC9K-Pro and pPIC9K-TG were constructed for expression of Pro- and TG genes, respectively (Fig.1). Both of the genes were inserted separately into pPIC9k vector, fused with the S. cerevisiae $\alpha$ mating factor signal sequence and regulated under AOX1 promoter. The pro and TG genes could be attached to rDNA and HIS4 loci of GS115 when vectors successfully transformed to the host strain.

In order to generate the co-expressing strain, the vector pPIC9k-Pro were first transformed to GS115 to make GS115-pro-rDNA host strain for TG.Successful clones of GS115-pro-rDNA were selected on yeast dextrose peptone (YPD) plate. The clone with pro-gene insertion were used as a host strain for pPIC9K-TG to form GS115(PrDNA/TGhIS4) co-expressing strain. The coexpressing strain GS115(PrDNA/TGhIS4) contains pro and TG genes were analyzed through PCR to verify the insertion (Fig.2a, and 2b).

Multi-copy integration is anticipated to occur by single homologous recombination during integration, resulting in tandem integrated copies of the vector ${ }^{20}$.The copy number of genes for TG expression is an important factor. In pichia pastoris, TG with 3 copy numbers recorded the best activity of $1.41 \mathrm{U} / \mathrm{ml}^{21}$.Therefore, the co-expression strain was selected on YPD with two concentration of G418 (contains $100 \mathrm{ug} / \mathrm{ml}, 150 \mathrm{ug} / \mathrm{ml}$ ) to ensure the successful transformant and appropriate copy number selection for TG expression. Strategy for multi-site integration of pro-region via rDNA and selection of an appropriate copy of TG produced $3.9 \mathrm{u} / \mathrm{ml}$ in the shake flask, indicating the role of pro-region in proper folding of more enzyme extracellularly (Fig $3 a$ and $3 b$ ).

\subsection{Effect of pH, Temp and different induction parameters on the TG activity}

The effects of three temperatures $\left(20^{\circ} \mathrm{C}, 25^{\circ} \mathrm{C}\right.$ and $\left.30^{\circ} \mathrm{C}\right)$ and four $\mathrm{pH}$ values (5.0, 6.0, 7.0 and 8.0) on TGproduction were tested in shake flask experiments using a single copy of the engineering strain GS115(PrDNA/TGhIS4). The clones were inoculated in $50 \mathrm{~mL}$ YPD for $24 \mathrm{hr}$ and the overnight cultures were transferred to $50 \mathrm{~mL}$ BMMY for $96 \mathrm{hr}$ induction. The samples were collected every $24 \mathrm{hr}$ and activity was measured by colorimetric hydroxamate-based method.

From the activity analysis, it appears that suitable environment for transglutaminase production is low temperature and alkaline environment from $\mathrm{pH}$ 6.5 7.5 as shown in (Fig 4a, 4b and 4c). The production of transglutaminases at a lower $\mathrm{pH}$ is difficult to enable activation and requires regulation of activation enzymes such as dispase I with exchange buffer.Lower temperatures are ideal for foreign proteins to reduce degradation, given theimportance of proteases. The finding in this research work may be due to the poor activity at low temperatures of extracellular protease enzymes.Higher temperatures are also problematic for the successful folding of foreign proteins ${ }^{22}$. Here, thesecretion of $\mathrm{TG}$ at temp $30^{\circ} \mathrm{C}$ is nearly the same as $25^{\circ} \mathrm{C}$, given the role of pro-region to enhance folding of TG amid higher temperature.

Three different induction parameters were chosen to see if different methanol intensities affect the engineering strain with pro-region higher integration at rDNA.In the shake flasks experiment, three different concentration, $0.5 \%, 1 \%$ and $1.5 \%$ of methanol were conducted. The product did not affect with methanol concentration from $0.5 \%$ to $1 \%$ but declined at higher concentration of $1.5 \%$, suggesting the accumulation of methanol which is toxic for the cells.

According to the data from shake flasks experiments, the recombinant strain expressed at higher level with low temperatures and higher $\mathrm{pH}$ values. However, the production at high temperature was nearly the same as at lower temperature compare to the wild type which showed little activity. The optimum extracellular production conditions for the engineering strain to produce the TG enzyme were therefore calculated at $20^{\circ} \mathrm{C}$ and $\mathrm{pH} 7$ at shake-flask level with $0.5 \%$ methanol induction. 

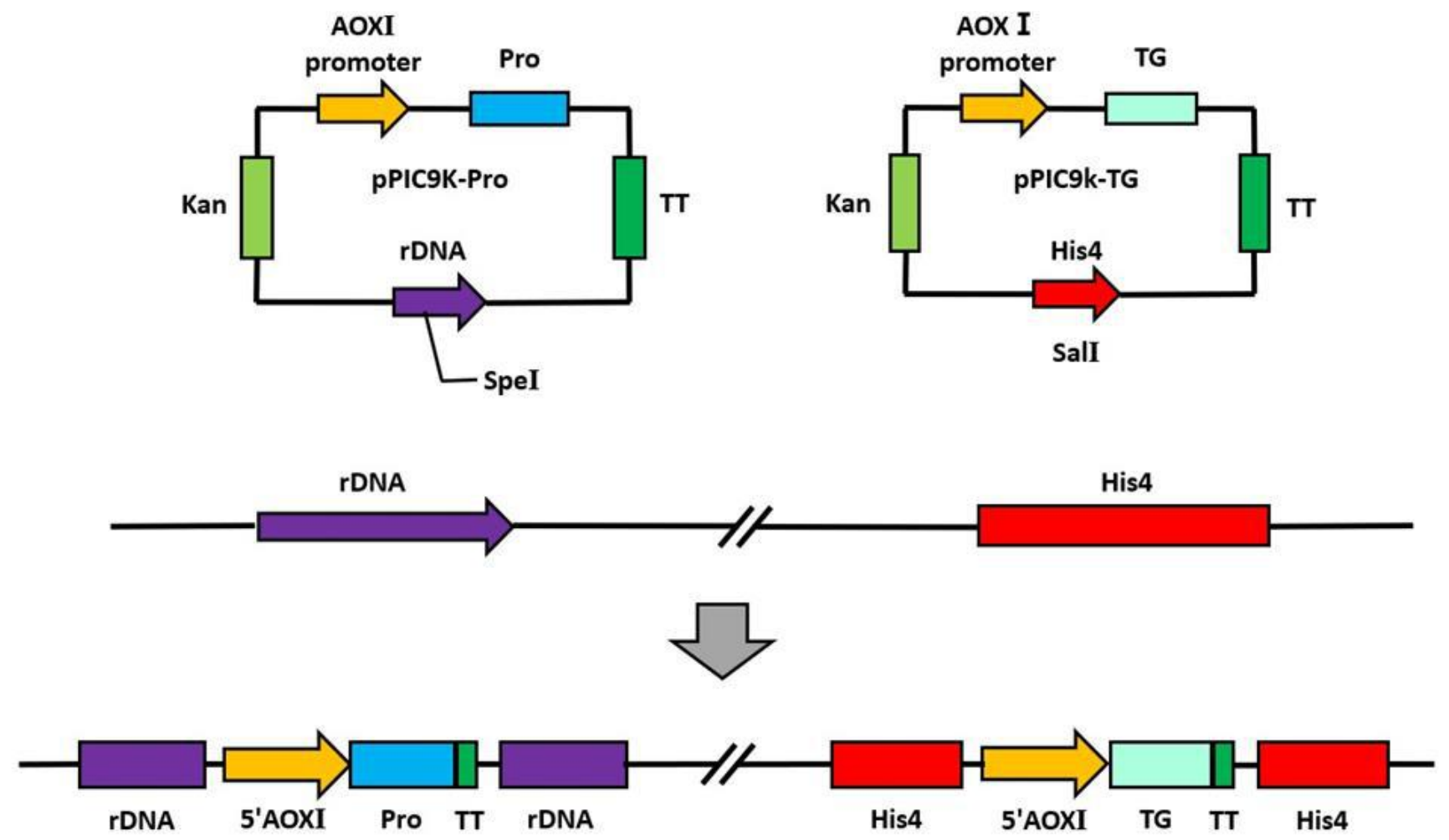

Fig.1 Construction of recombinant plasmids for TG expression

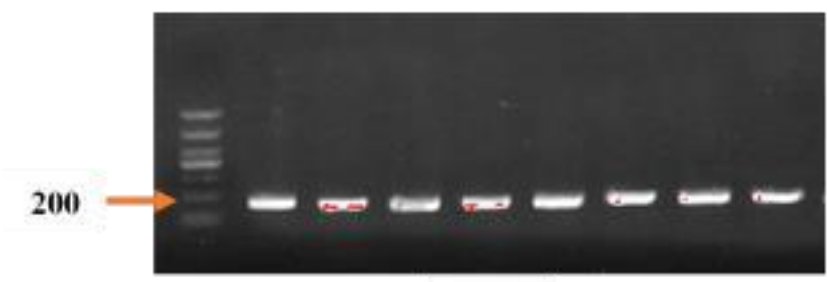

(a)

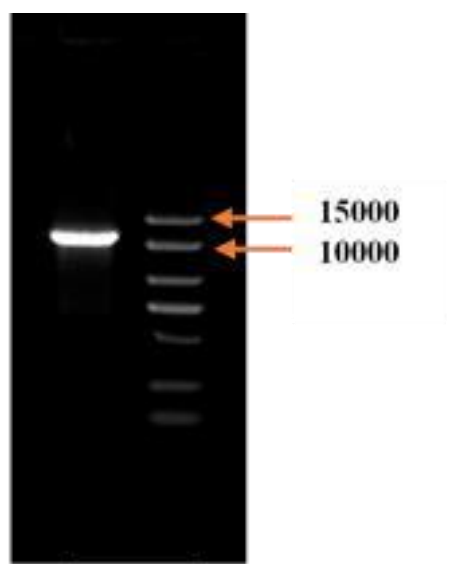

(b)

Fig. 2 Colony PCR from the host strain GS115-prorDNA showing pro region having 135bp (a). The TG gene having 1135bp from co-expressing strain GS115(PrDNA/TGhIS4) (b). 


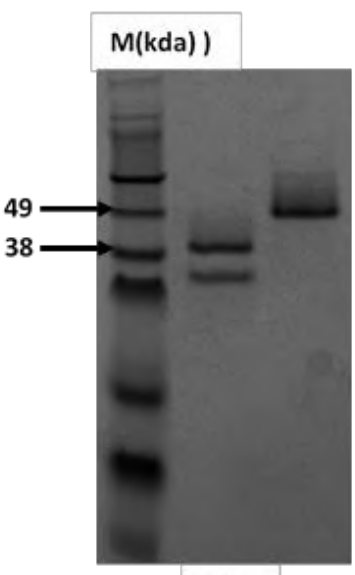

(a)

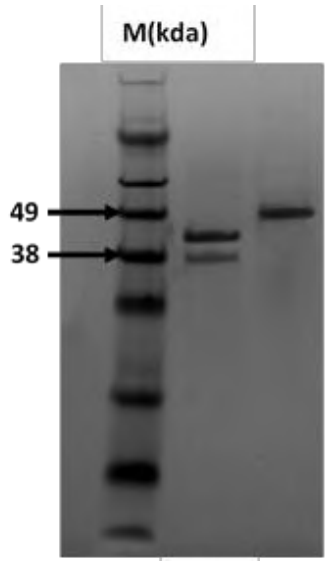

(b)

Fig. 3 The SDS analysis of wild type and co-expressing engineered strain. Both of the expression were treated with and without dispase I. (a) Wild type TG, lane 1 is treated with dispase showing 40kda while lane 2 is without any dispase addition shows 55kda. (b) Co-expressed GS115(PrDNA/TGhIS4) strain, lane 1 is treated with dispase showing 40kda while lane 2 is without any dispase addition shows 55kda. Here, the engineered strain shows big bands suggesting more of the proteins secreted in the extracellular matrix
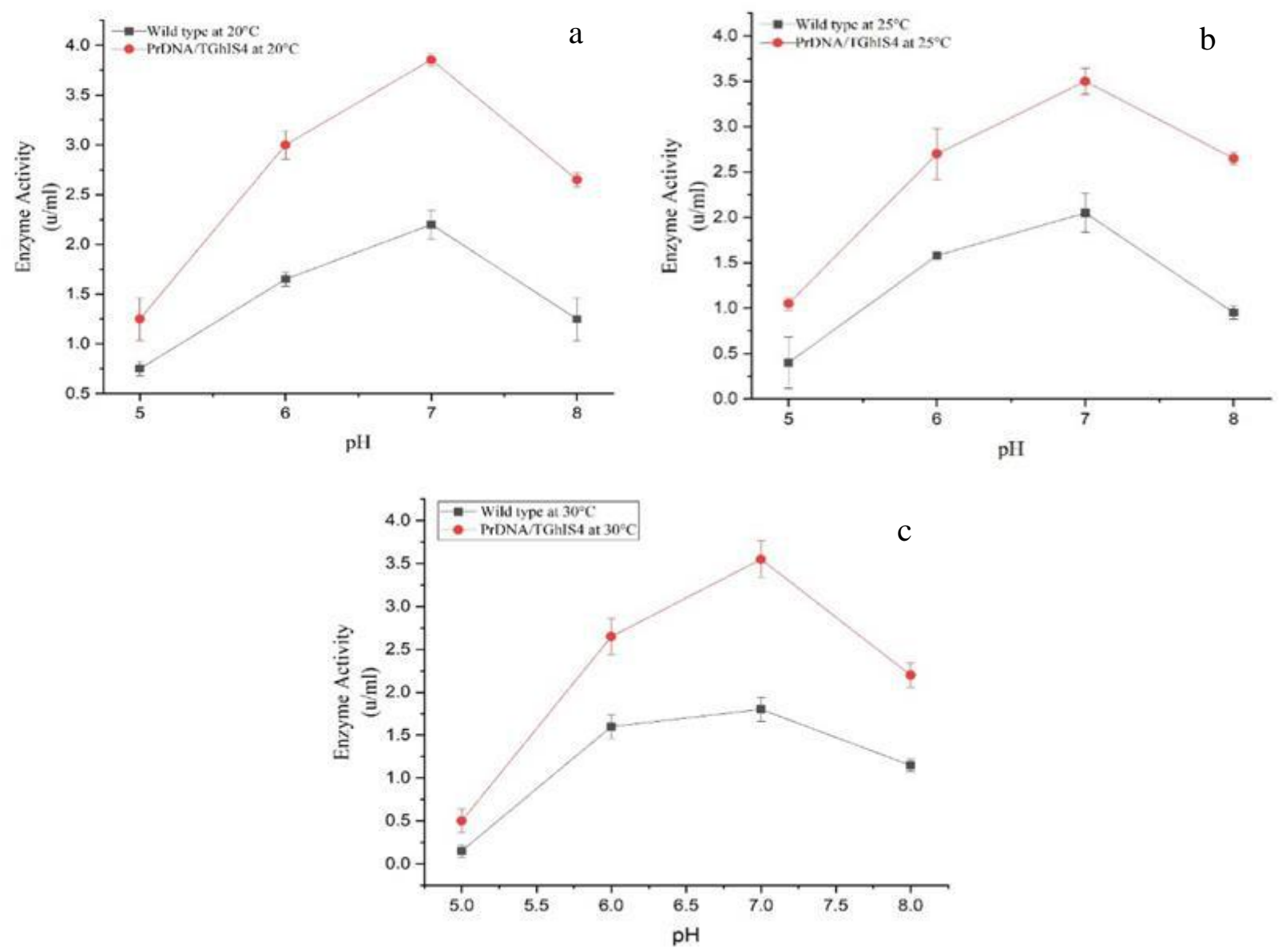

Fig. 4: Activity analysis of wild type TG and GS115(PrDNA/TGhIS4) engineered strain at three different temperatures (a)20 ${ }^{\circ} \mathrm{C}$, (b) $25^{\circ} \mathrm{C}$, and (c) $30^{\circ}$ Cand four different $\mathrm{pH}$ values. 


\section{CONCLUSION}

The co-expression strain GS115(PrDNA/TGhIS4) was successfully engineered by integrating the pro-region at nontranscribed ribosomal rDNA of pichia pastoris followed by TG incorporation into his4 site. The expression of pro-region with uncountable copies at rDNA sites secreted more folded extracellular proteins. However, for industrial applications, the output of this study work is minimal, and needs to be improved.It offered an insight for potential pro-region enhancement and secretion investigation.Co-expression of pro-region and mTG is a challenging task. These findings could be applied and expanded by harnessing the pro-region role for the folding of "difficult-to-express" recombinant coexpress pro-transglutaminase.

\section{ACKNOWLEDGMENT}

This work was supported by National Key Research and Development Program

China (No. 2019YFA0706900 and 2019YFA0905300);

the National Natural Science Foundation of China (No. 31771913); the National First-class Discipline Program of Light Industry Technology and Engineering (No. LITE2018-08); the Scientific and Technological Innovation Major Base of Guangxi (No. 2018-15-Z03); and the Fundamental Research Funds for the Central Universities (No. JUSRP52026A).

VI.

\section{REFERENCES}

[1] Ohtsuka, T.; Ota, M.; Nio, N.; Motoki, M. Comparison of Substrate Specificities of Transglutaminases Using Synthetic Peptides as Acyl Donors. Bioscience, Biotechnology and Biochemistry. 2000, pp 2608-2613. https://doi.org/10.1271/bbb.64.2608.

[2] Esposito, C.; Caputo, I. Mammalian Transglutaminases: Identification of Substrates as a Key to Physiological Function and Physiopathological Relevance. FEBS J.2005, 272 (3), 615-631. https://doi.org/10.1111/j.17424658.2004.04476.x.

[3] Griffin, M.; Casadio, R.; Bergamini, C. M. Transglutaminases: Nature's Biological Glues. Biochem. J.2002, 368 (2), 377396. https://doi.org/10.1042/BJ20021234.

[4] Folk, J. E. 1. 517. 1980.

[5] Shlě̌kin, A. G.; Danilov, N. P. [Evolutionary-Biological Peculiarities of Transglutaminase. Structure, Physiological Functions, Application]. Zh. Evol. Biokhim. Fiziol.2011, 47 (1), 3-14.

[6] Heck, T.; Faccio, G.; Richter, M.; Thöny-Meyer, L. EnzymeCatalyzed Protein Crosslinking. Appl. Microbiol. Biotechnol.2013, $97 \quad$ (2), 461-475. https://doi.org/10.1007/s00253-012-4569-z.

[7] Serafini-Fracassini, D.; Del Duca, S. Transglutaminases: Widespread Cross-Linking Enzymes in Plants. Ann. Bot.2008, 102 (2), 145-152. https://doi.org/10.1093/aob/mcn075.

[8] Yang, M. Te; Chang, C. H.; Wang, J. M.; Wu, T. K.; Wang, Y. K.; Chang, C. Y.; Li, T. H. T. Crystal Structure and Inhibition Studies of Transglutaminase from Streptomyces Mobaraense. J. Biol. Chem.2011, 286 (9), 7301-7307. https://doi.org/10.1074/jbc.M110.203315.

[9] Yokoyama, K.; Nio, N.; Kikuchi, Y. Properties and Applications of Microbial Transglutaminase. Appl. Microbiol. $\begin{array}{llll}\text { Biotechnol.2004, } & 64 & \text { (4), }\end{array}$ https://doi.org/10.1007/s00253-003-1539-5.

[10] Zhu, Y.; Tramper, J. Novel Applications for Microbial Transglutaminase beyond Food Processing. Trends Biotechnol.2008, $\quad 26 \quad$ (10), 559-565. https://doi.org/10.1016/j.tibtech.2008.06.006.

[11] Kieliszek, M.; Misiewicz, A. Microbial Transglutaminase and Its Application in the Food Industry. A Review. Folia Microbiol. $\quad$ (Praha).2014, $59 \quad$ (3), 241-250. https://doi.org/10.1007/s12223-013-0287-x.

[12] Ando, H.; Adachi, M.; Umeda, K.; Matsuura, A.; Nonaka, M.; Uchio, R.; Tanaka, H.; Motoki, M. Purification and Characteristics of a Novel Transglutaminase Derived from Microorganisms. Agric. Biol. Chem.1989, 53 (10), 26132617. https://doi.org/10.1080/00021369.1989.10869735.

[13] Dennler, P.; Chiotellis, A.; Fischer, E.; Brégeon, D.; Belmant, C.; Gauthier, L.; Lhospice, F.; Romagne, F.; Schibli, R. Transglutaminase-Based Chemo-Enzymatic Conjugation Approach Yields Homogeneous Antibody-Drug Conjugates. Bioconjug. Chem.2014, $25 \quad$ (3), 569-578. https://doi.org/10.1021/bc400574z.

[14] Baker, D.; Shiau, A. K.; Agard, D. A. The Role of pro Regions in Protein Folding. Curr. Opin. Cell Biol.1993, 5 (6), 966-970. https://doi.org/10.1016/0955-0674(93)90078-5.

[15] Eder, J.; Fersht, A. R. Pro-sequence-assisted Protein Folding. Mol. Microbiol.1995, 16 (4), 609-614. https://doi.org/10.1111/j.1365-2958.1995.tb02423.x.

[16] Türkanoğlu Özçelik, A.; Ersöz, F.; İnan, M. Extracellular Production of the Recombinant Bacterial Transglutaminase in Pichia Pastoris. Protein Expr. Purif.2019, 159 (March), 8390. https://doi.org/10.1016/j.pep.2019.03.003.

[17] Yurimoto, H.; Yamane, M.; Kikuchi, Y.; Matsui, H.; Kato, N.; Sakai, Y. The Pro-Peptide of Streptomyces Mobaraensis Transglutaminase Functions in Cis and in Trans to Mediate Efficient Secretion of Active Enzyme from Methylotrophic Yeasts. Biosci. Biotechnol. Biochem.2004, 68 (10), 20582069. https://doi.org/10.1271/bbb.68.2058.

[18] Li, H.; Fan, H.; Li, Y.; Shi, G. Y.; Ding, Z. Y.; Gu, Z. H.; Zhang, L. Construction and Application of Multi-Host Integrative Vector System for Xylose-Fermenting Yeast. FEMS Yeast Res.2017, $17 \quad$ (6). https://doi.org/10.1093/femsyr/fox055.

[19] Yabuta, Y.; Takagi, H.; Inouye, M.; Shinde, U. Folding 
Pathway Mediated by an Intramolecular Chaperone: Propeptide Release Modulates Activation Precision of proSubtilisin. J. Biol. Chem.2001, 276 (48), 44427-44434. https://doi.org/10.1074/jbc.M107573200.

[20] Lynn E Murry, Laurie G Elliott, Sherry A Capitant, Joanne A West, Kimberly K Hanson, Liliana Scarafia, Scott Johnston, Camille DeLuca-Flaherty, Scott Nichols, Dolores Cunanan, Paul S Dietrich, Irvin J Mettler, Steve Dewald, Debra A Warnick, Carol Rhodes, and K. J. B. (C) 1993 Nature Publishing Group Http://Www.Nature.Com/Naturebiotechnology. Nat. Biotechnol.1993, 11, 159-1564. https://doi.org/10.1038/ng0293-165.

[21] Song, X.; Shao, C.; Guo, Y.; Wang, Y.; Cai, J. Improved the Expression Level of Active Transglutaminase by Directional Increasing Copy of Mtg Gene in Pichia Pastoris. BMC Biotechnol.2019, 19 (1), 1-9. https://doi.org/10.1186/s12896019-0542-6.

[22] Dragosits, M.; Stadlmann, J.; Albiol, J.; Baumann, K.; Maurer, M.; Gasser, B.; Sauer, M.; Altmann, F.; Ferrer, P.; Mattanovich, D. The Effect of Temperature on the Proteome of Recombinant Pichia Pastoris. J. Proteome Res.2009, 8 (3), 1380-1392. https://doi.org/10.1021/pr8007623. 